\title{
ORIENTAÇÕES CURRICULARES DE GEOGRAFIA E EDUCOPÉDIA DA SECRETARIA MUNICIPAL DE EDUCAÇÃO DO RIO DE JANEIRO
}

\author{
ORIENTACIONES CURRICULARES DE GEOGRAFÍA Y EDUCIÓN DE \\ LA SECRETARÍA MUNICIPAL DE EDUCACIÓN DEL RÍO DE JANEIRO
}
CURRICULAR GUIDELINES OF GEOGRAPHY AND EDUCOPÉDIA OF THE MUNICIPAL SECRETARIAT OF EDUCATION OF RIO DE JANEIRO

\author{
Renata Bernardo ANDRADE ${ }^{1}$ \\ Ana Claudia Ramos SACRAMENTO2
}

RESUMO: Este trabalho tem como objetivo refletir sobre o currículo como instrumento ideológico e conceitual de formação do conhecimento, a partir da importância do currículo de Geografia e sua importância na escola, ao tecer considerações a respeito de que concepções de disciplina desenvolver para pensar uma visão de mundo e raciocínio crítico nos alunos. Assim, a partir das Orientações Curriculares de Geografia da Secretaria Municipal de Educação do Rio de Janeiro analisar o papel da disciplina, partir do uso da Educopédia, uma plataforma on line organizada a partir de disciplinas por séries com conteúdos e materiais de apoio para os professores. Como resultados analisa-se que as Orientações Curriculares são construídas a partir de uma teoria curricular tradicional, caracterizado por uma organização curricular por competências na qual a disciplina ainda se mostra de maneira tradicional do conhecimento geográfico.

PALAVRAS-CHAVE: Currículo. Ensino de Geografia. Orientações Curriculares. Educopéia.

RESUMEN: Este trabajo tiene como objetivo reflexionar sobre el currículo como instrumento ideológico y conceptual de formación del conocimiento, a partir de la importancia del currículo de Geografía y su importancia en la escuela, al tejer consideraciones acerca de qué concepciones de disciplina desarrollar para pensar una visión de mundo Y raciocinio crítico en los alumnos. A partir de las Orientaciones Curriculares de Geografía de la Secretaría Municipal de Educación de Río de Janeiro analizar el papel de la disciplina, desde el uso de la Educación, una plataforma on line organizada a partir de disciplinas por series con contenidos y materiales de apoyo para los profesores. Como resultados se analiza que las Orientaciones Curriculares se construyen a partir de una teoría curricular tradicional, caracterizado por una organización curricular por competencias en la cual la disciplina todavía se muestra de manera tradicional del conocimiento geográfico.

\footnotetext{
${ }^{1}$ Universidade Estadual do Rio de Janeiro (Uerj), Rio de Janeiro - RJ - Brasil. Mestranda em geografia DGEO-FFP UERJ. E-mail: prof.renata.geo@gmail.com.

${ }^{2}$ Universidade Estadual do Rio de Janeiro (Uerj), Rio de Janeiro - RJ - Brasil. Professora de Graduação e Pós-Graduação em Geografia- DGEO-FFP UERJ. Doutora em Geografia Física - DGEO-FFLCH-USP. E-mail: anaclaudia.sacramento@hotmail.com.
}

RIAEE - Revista Ibero-Americana de Estudos em Educação, Araraquara, v. 13, n. 1, p. 248-268, jan./mar., 2018. 
PALABRAS CLAVE: Currículo. Enseñanza de Geografía. Orientaciones Curriculares. Educopéia.

ABSTRACT: This work aims to reflect on the curriculum as an ideological and conceptual instrument of knowledge formation, based on the importance of the curriculum of Geography and its importance in school, by making considerations about which conceptions of discipline develop to think a worldview and critical thinking in students. Thus, from the Curriculum Guidelines of Geography of the Municipal Department of Education of Rio de Janeiro analyze the role of the discipline, starting from the use of Educopédia, an online platform organized from disciplines by series with content and support materials for teachers. As results, it is analyzed that the Curricular Guidelines are constructed from a traditional curricular theory, characterized by a competency curricular organization in which the discipline still shows itself in the traditional way of the geographical knowledge.

KEYWORDS: Curriculum. Teaching Geography. Curricular Guidelines. Educopédia

\section{Introdução}

As reformas educacionais recentes desenvolvidas em diferentes países do ocidente foram marcadas por mudanças na organização dos currículos, os quais passaram a explicitar a valorização da formação de competências e habilidades necessárias às mudanças tecnológicas no mundo global.

Em meio às ondas de mudanças, observadas no cenário nacional desde os anos de 1990, verificou-se que os novos paradigmas do mundo contemporâneo estão relacionados às mudanças nas políticas públicas educacionais, as quais reorientadas a partir do sistema neoliberal enfatizam a importância de uma escola de qualidade, eficiente e de preparação para o mercado de trabalho.

Como resultado desse processo, os Estados acabaram também por construir os seus currículos em consonância com as Políticas Curriculares Nacionais e Internacionais. Esse foi o caso das Orientações Curriculares da Secretaria de Educação do Municipio do Rio de Janeior (SME-RJ), 2016 que conjuntamente com a criação do Educopéia, plataforma on line desenvolvida para auxiliar nas aulas dos professores, buscam repensar a educação do município.

A partir das discussoões da disicplina Geografia, parte deste documento curricular e da Educopédia, o objetivo deste texto é refletir sobre a importância de pensar o currículo como um instrumento ideológico e conceitual, tendo como objetos as Orientações Curriculares de Geografia e o Educopédia de Geografia.

RIAEE - Revista Ibero-Americana de Estudos em Educação, Araraquara, v. 13, n. 1, p. 248-268, jan./mar., 2018. 
Desta maniera, o texto está dividido em três momentos: o primeiro na qual é realizado uma abordagem sobre o currículo a partir do seu significado, das teorias e organizações curriculares; segundo, importância do currículo de Geografia e a importância da disciplina na escola e por fỉm, a análise empírica das Orientações Curriculares de Geografia e da Educopédia da Geografia da SME-RJ.

\section{Abordagens acerca do currículo}

O currículo escolar aparece pela primeira vez, como objeto de estudo e pesquisa, na década de 1920, nos Estados Unidos (SILVA, 1999). As preocupações daí advindas visavam atender ao processo de industrialização e aos intensos movimentos migratórios do campo para a cidade, com a intensificação da escolarização em massa. Dessa forma, as pessoas envolvidas na administração da educação, a fim de conferir maior racionalidade à educação em massa, estabeleceram um processo de construção, desenvolvimento e testagem de currículos.

De acordo com Malta (2013) o primeiro autor sobre o tema foi Bobbit (1918) que escreveu sobre currículo num momento nos quais diversas forças políticas, econômicas e culturais procuravam desenvolver a educação de massas para garantir que sua ideologia fosse garantida. Bobbit (1918) propunha que a escola funcionasse como umaindustrial sendo o currículo uma questão de organização dos conteúdos considerados relevantes ocorrendo de forma mecânica e burocrática.

Silva (1999) afirma que Bobbit, no livro The curriculum (1918) compreende o currículo escolar como um processo de racionalização de resultados educacionais, rigorosamente especificados e medidos. O modelo institucional dessa concepção de currículo é a fábrica.

Silva (1999, p.15) a epistemologia da palavra currículo, que vem, do latim curriculum "pista de corrida", caminho, jornada, trajetória, percurso a seguir. No currículo é preciso traçar planos, ter metas, saber os objetivos e saber fazê-los para que no fim sua "jornada" ou sua "trajetória" seja completa e satisfatória, ou seja, fazer o currículo é saber qual a sua intenção, de que forma construí-lo e para que fim.

Um discurso sobre o currículo, mesmo que pretenda apenas descrevêlo tal como ele realmente é o que efetivamente faz é produzir uma noção particular de currículo. A suposta descrição é efetivamente, uma criação... Aquilo que Bobbit dizia ser o currículo passou efetivamente a ser o currículo as chamadas teorias de currículo assim

RIAEE - Revista Ibero-Americana de Estudos em Educação, Araraquara, v. 13, n. 1, p. 248-268, jan./mar., 2018. 
como as teorias educacionais estão recheadas de afirmações sobre como as coisas deveriam ser. (SILVA, 1999, p.13).

Os currículos têm por objetivo orientar a construção do conhecimento escolar. É por meio deles que são regidas a teoria e a prática de todo o processo no ambiente e a dinâmica do tipo de ensino que a escola oferece. Não são simplesmente desenhos curriculares, mas são as transformações de todo um contexto: para que se ensina, do que se ensina e qual a intenção política e social que se irá contemplar.

Assim como para Lopes e Macedo:

Assim como as tradições que definem o que é o currículo, o currículo é, ele mesmo, uma prática discursiva. Isso significa que ele é uma prática de poder, mas também uma prática de significação, de atribuição de sentidos. Ele constrói a realidade, nos governos, constrange nosso comportamento, projeta nossa identidade, tudo isso produzindo sentidos. Trata-se, portanto, de um discurso produzido entre diferentes discursos sociais e culturais que, ao mesmo tempo, reitera sentidos postos por tais discursos e os recria. (LOPES; MACEDO, 2011, p. 41)

Para as autoras o currículo carrega vários significados porque ele faz parte de um conjunto de práticas de poder, de significação, de sentidos que não dá para simplificar, uma vez que ele tem voz a partir de diferentes concepções dos discursos. Assim, ele é importante do ponto de vista político, porque ele projeta a forma como os detentores do poder querem legitimar um determinado sentido, um determinado discurso ou produção de discursos e práticas.

Pode-se dizer que ao conceitualizar o currículo pode-se compreender diferentes contextos históricos, a partir das formas políticas, econômicas, culturais, sociais que acabam direcionando as organizações curriculares de uma disciplina, bem como a escolha dos conceitos e conteúdos e a dinâmica escolar. Assim como diz Lopes; Macedo (2011, p. 40)

Cada uma das tradições curriculares é um discurso que se hegemonizou e que, nesse sentido, constituiu o objeto currículo, emprestando-lhe um sentido próprio. Tais tradicionais não se captam, de diferentes maneiras, um sentido para o termo. Elas os constroem, criam um sentido sobre o ser o currículo.

Desta forma, a partir da lógica do momento de uma dada realidade que se constitui uma forma de legitimar a construção histórica que foi se determinando ao longo do tempo para pensar o sentido de se estruturar o documento curricular. Essas 
tradições são expressões daquilo que se mudou de acordo com as necessidades do mundo de cada época, de sua cultura, de sua economia e outros.

Existem diversas concepções e conceituações de currículo em diferentes momentos históricos, mas Silva (1999) aponta como questão central que serve de pano de fundo para as teorias do currículo é a de saber: Qual conhecimento deve ser ensinado?

Para responder a essa questão as diferentes teorias podem recorrer a discussões sobre a natureza humana, sobre a natureza da aprendizagem ou sobre a natureza do conhecimento, da cultura e da sociedade. As teorias se diferenciam, inclusive pela ênfase que dão a esses elementos. Ao final, elas retornam a questão básica; O que eles ou elas devem saber? Qual o conhecimento ou saber é considerado importante para merecer ser considerada parte do currículo? (SILVA, 1999, p.14).

Essas perguntas nos revelam segundo o autor que as teorias do currículo têm o interesse em desenvolver critérios de seleção que justificam a resposta que darão àquelas questões. Nas teorias do currículo, a pergunta “o quê?” Nunca é separada de outra importante pergunta: “O que os alunos devem se tornar?” Afinal o currículo busca modificar as pessoas que vão seguir aquele currículo.

Atualmente apresenta-se uma nova perspectiva de educação, não apenas com objetivos de transmissão de conteúdos, por isso entendemos que o currículo é cheio de intenções e significados. Que compreende relações de poder, envolvendo aquilo que somos e em que nos tornamos. As principais teorias de currículo são: tradicional; critica e pós-crítica.

A teoria tradicional para Malta (2013) procura ser "neutra", tendo como principal foco identificar os objetivos da educação escolarizada, formar o trabalhador especializado ou proporcionar a população uma educação geral, acadêmica. Seus principais autores foram Bobbit, Tyler e Dewey, mas a questão principal das teorias tradicionais pode ser assim resumida: conteúdos, objetivos e ensino destes conteúdos de forma eficaz para ter a eficiência nos resultados.

As teorias críticas se preocupam em desenvolver conceitos que permita compreender, com base em uma análise marxista, qual a função do currículo escolar questionando a ligação entre educação e ideologia. De acordo com Malta (2013) é através do currículo a ideologia dominante transmite seus princípios, por meio das disciplinas e conteúdos que reproduzem os mecanismos seletivos que fazem com que crianças de famílias menos favorecidas saiam da escola antes de chegaram a aprender as

RIAEE - Revista Ibero-Americana de Estudos em Educação, Araraquara, v. 13, n. 1, p. 248-268, jan./mar., 2018. 
habilidades próprias das classes dominantes, e por práticas discriminatórias que levam as classes dominadas a submissão e obediência a classe dominante. Assim as escolas reproduziriam os aspectos necessários para a sociedade capitalista: trabalhadores adequados a cada necessidade dos locais de trabalho, líderes obedientes e subordinados para os cargos de produção.

\begin{abstract}
A reprodução social ocorre por meio da cultura através da reprodução cultural; que pela transmissão da cultura dominante fica garantida a sua hegemonia; que o que tem valor é a cultura dominante, com os seus valores, os seus gostos, costumes e hábitos que passam a ser considerados cultura, desprezando-se os costumes e valores das classes dominadas. (MALTA, 2013, p. 346).
\end{abstract}

A ênfase das teorias críticas estava no significado subjetivo dado à experiência pedagógica e curricular de cada indivíduo. Malta (2013) aponta que a seleção que compõe o currículo é resultado de um processo que reflete os interesses particulares das classes dominantes. A questão não é apenas qual conhecimento é verdadeiro, mas qual é considerado verdadeiro e quem o considera verdadeiro. Assim o importante seria analisar tanto valores, normas e disposições, quanto os pressupostos ideológicos das disciplinas que constituem o currículo oficial. A escola além de transmitir conhecimento, deve ser também, produtora de conhecimentos.

A questão básica era a conexão entre currículo e poder, entre a organização do conhecimento e a distribuição de poder. Por que era atribuída mais importância a certas disciplinas e conhecimentos do que a outros.

As teorias pós-críticas analisaram o currículo multiculturalista com sua diversidade das formas culturais do mundo contemporâneo. O multiculturalismo aparece como movimento contra o currículo que privilegia a cultura branca, masculina, européia e heterossexual, a cultura do grupo social dominante. A partir dessa análise, para Malta (2013) houve a proposição de um currículo que também incluísse aspectos de formas mais representativas das diversas culturas dominadas.

É essencial por meio de o currículo desconstruir o texto racial, questionar por que e como valores de certos grupos étnicos e raciais foram desconsiderados ou menosprezados no desenvolvimento cultural e histórico da humanidade e, pela organização do currículo, proporcionar os mesmos significados e valores a todos os grupos, sem supervalorização de um ou de outro. (MALTA, 2013, p. 351). 
Na visão pós-estruturalista o debate não busca saber se algo é verdadeiro, mas saber por que esse algo se tornou verdadeiro. Essa perspectiva coloca em dúvida as atuais e rígidas separações curriculares, além de todo o conhecimento. Já para Malta (2013) juntamente com o feminismo e com o movimento negro, como objetivo estudar as relações de poder entre nações que compõem a herança econômica, política e cultural de seus países colonizadores questionou as relações de poder e as formas de conhecimento pelas quais a posição européia se mantém privilegiada.

Para Silva (1999, p.16) as teorias tradicionais se preocupam com questões de organização. A teoria crítica e pós-críticas por sua vez não se limitam a perguntar "o que?", mas submetem este o que a um constante questionamento o que, mas por quê? Por que esse conhecimento e não outro? Quais os interesses fazem com que esse conhecimento e não outro esteja no currículo? Por que privilegiar um determinado tipo de identidade ou subjetividade e não outro? Estas teorias estão preocupadas com as conexões entre saber, identidade e poder.

O currículo está diretamente relacionado a um projeto de homem e de sociedade, "se identifica o currículo servindo aos valores, interesses de uma determinada sociedade." (MALTA, 2013, p.342). O currículo também pode ser analisado a partir das matrizes clássicas da organização curricular, Lopes (2008) destaca a existência de: currículo por competências; o currículo centrado nas disciplinas de referência e o currículo centrado nas disciplinas escolares.

O currículo por competências é apreendido como comportamentos, cientificamente controláveis e mensuráveis, a ação é executada com base em dadas habilidades, possibilitando indicadores de desempenho para avaliação. Segundo Lopes (2008), esta matriz tem com parâmetro um saber-fazer ao mundo produtivo e regido por um conhecimento especializado, tendendo a desconsiderar as relações sociais cotidianas dos indivíduos que são substituídos por competências técnicas derivadas dos saberes especializados.

O currículo centrado nas disciplinas de referência se baseia na estruturação das disciplinas, pois cada disciplina tem sua particularidade, facilitando o acesso ao aluno. Segundo Lopes (2008), compreender a estrutura da disciplina permite ao aluno compreender como a disciplina trabalha: entender seus problemas, as questões metodológicas e conceituais. Nessa lógica o ensino deve transmitir os conhecimentos das disciplinas de referências.

RIAEE - Revista Ibero-Americana de Estudos em Educação, Araraquara, v. 13, n. 1, p. 248-268, jan./mar., 2018. 
O currículo centrado nas disciplinas escolares é definido em função das finalidades sociais a serem atendidas, e não em função das disciplinas de referência. Segundo Lopes (2008) o currículo é composto de atividades que visam desenvolver a vida social e comunitária. O significado do currículo é orientar como a escola deve se organizar para estabelecer determinados parâmetros para pensar e estruturar as orientações político-pedagógicas, administrativas e sociais com o propósito de legitimar o papel da escola enquanto um espaço sócio- cultural- educativo.

Desta forma, todas as pessoas envolvidas na elaboração de um currículo, não o fazem de maneira neutra. Tornando, o currículo escolar impregnado de valores, ideologias, forças e interesses. Entender essa dinâmica é importante para professor, uma vez que o currículo se operacionalizará durante a aula e em diversos espaços da escola. Assim a cada época o currículo se modifica de acordo com o poder vigente, com pensamento e tipo de estrutura escolar que a sociedade e o governo desejam.

O currículo escolar não é somente um discurso, mas é um artefato social que organiza a forma estrutural do ambiente escolar e, principalmente, o tipo de saber que se deseja transmitir. Contudo, quando entendemos que a educação deve opor-se a ideologia dominante, os conhecimentos privilegiados devem ser aqueles que formem pessoas desconfiadas e críticas dos arranjos sociais existentes.

\section{O Currículo e Ensino de geografia}

O currículo da Geografia é um artefato político, social, educacional de possibilita de proporcionar aos alunos, valores, conhecimentos e outros aspectos relevantes na construção dos conhecimentos geográficos. Para pensar sobre um currículo é preciso responder algumas questões, privilegiando assim alguns conteúdos em relação a outros. Deste modo, esse movimento de questionar quais os conteúdos relevantes devem ser aplicados à elaboração de um currículo de Geografia.

O que ensinar em geografia? É uma pergunta que deve ser feita pelos docentes desta disciplina, é importante ainda - dentro de um viés da teoria crítica do currículo se questionar sobre o por quê ? Por que ensinar geografia? Por que devo ensinar este e não aquele conteúdo da geografia?É preciso ter clareza da diferença entre geografia acadêmica e a geografia escolar, é importante para que o professor de geografia da escola básica saiba o propósito da geografia no ensino. O que se pretende ao ensinar geografia na escola básica?

RIAEE - Revista Ibero-Americana de Estudos em Educação, Araraquara, v. 13, n. 1, p. 248-268, jan./mar., 2018. 
Sendo assim, a geografia escolar ainda é vista como uma disciplina enfadonha de memorização de determinadas informações geográfica tornando-se uma disciplina voltada para a simples descrição de mundo. Lacoste (2012) denomina geografia dos professores, o método de investigação positivista, que se organiza metodologicamente no modelo de Natureza- Homem -Economia N-H-E apresentado por MOREIRA (2014).

Uma geografia descritiva, com valorização do empírico como discurso pedagógico enciclopédico. Ou seja, "pela estruturação mecânica de fatos, fenômenos e acontecimentos divididos em aspectos físicos, aspectos humanos e aspectos econômicos [...]" (CAVALCANTI, 2013, p. 20).

Nas palavras de Lacoste (2012), a Geografia é um conhecimento estratégico para determinações de poder, mas ocultado pela geografia escolar que não garante aos alunos a capacidade de ler as representações espaciais.

Para Castellar(2013), a Geografia no currículo escolar precisa superar a geografia dos professores, "estudar geografia é uma oportunidade para entendermos o mundo em que vivemos, visto que essa disciplina refere-se às ações humanas construídas em diferentes sociedades e lugares.” (p. 1).

No currículo escolar, esta disciplina possibilita ao aluno desenvolver um raciocínio espacial, compreensão dos lugares em diferentes escalas, auxiliando-o a localizar e criar conexões entre os "lugares da superfície da Terra de forma criteriosa e com o devido rigor científico." Assim, conforme Castellar; Stefenon (2015) afirmam que dentro do currículo de Geografia precisa pautar a necessidade dos estudantes em compreender as categorias, conceitos, conteúdos, fenômenos e fatos geográficos, do ponto de vista científico, é parte de um currículo geográfico escolar que tenha a dimensão conceitual bem como do didático-pedagógico articulados, para desenvolver o conhecimento dos estudantes.

\begin{abstract}
Ao assumirmos a ideia de que o currículo precisa ser organizado conceitualmente e com conteúdos que provoquem o desenvolvimento da capacidade intelectual dos alunos, apontamos na direção de um currículo fundamentado no conhecimento disciplinar. Dentro dessa concepção, de modo essencial, a escola se coloca como uma instituição capaz de oferecer aos jovens, independentemente de sua origem identitária ou social, o acesso ao saber considerado essencial à sua inclusão no mundo (CASTELLAR; STEFENON, 2015, p. 22)
\end{abstract}

Desta maneira, o currículo precisa construir um conhecimento crítico para mobilizar os estudantes a serem capazes de desenvolver a leitura espacial. Cavalcanti 
(2012) aponta a geografia enquanto uma forma de leitura da realidade, que pode ser alcançada por um conjunto de interrogações sobre os fenômenos do mundo, isto é, "questões elencadas como típicas da geografia - Onde? Por que nesse lugar? Como é esse lugar?" (p. 135).

Esse caminho é uma forma de diferenciar a abordagem da geografia na escola, apresentando, assim, um modo de pensar sobre algo, construindo um raciocínio geográfico, na qual precisa desenvolver capacidade nos estudantes de pensar teoricamente para analisar a realidade e a espacialidade dos fenômenos naturais e sociais, de forma crítica.

Os conteúdos da geografia escolar devem ensinar aos alunos uma maneira de ver o mundo, ensinando um modo de pensar geográfico, que os possibilitem aprender a ler a espacialidade diferencial, as origens naturais, sociais, políticas e econômicas da desigual produção do espaço. Estimular o olhar do aluno, para a compreensão do espaço como produto e produtor das relações existentes na sociedade e da sua forma de organização.

Baseado em um raciocínio geográfico, estabelecer conexões existentes entre as escalas, do local ao global retornando ao local, para poder aplicar uma leitura crítica a sua realidade. Também deve ser compreendido que a exigência de aprofundamento na ciência geográfica não é tão necessária à escola. Na verdade, é preciso re-contextualizar os conteúdos da ciência geográfica às necessidades da geografia escolar, em função da realidade do aluno e de sua prática espacial, para que o ensino desta disciplina possa alcançar seus objetivos. Cabe ao professor executar este movimento, mas para tal, é necessário que o professor tenha clareza e coerência metodológica.

Cavalcanti (2012) aponta que os professores de geografia estão sempre procurando novas e diferentes formas de trabalhar e ensinar, novos materiais, novos recursos; novas metodologias. Entretanto os professores têm pouco espaço e tempo em sua jornada de trabalho para a reflexão no sentido de detectar suas dificuldades e conquistas. E que Tais momentos podem ser considerados formação continuada, mas geralmente não é isso que acontece. 
Os professores, para definição dos conteúdos a ensinar, seguem basicamente o que está estabelecido no livro didático ou nos programas curriculares da escola ou das secretarias de ensino o que pode ser interpretado como dificuldade de estabelecer o que é importante nos conteúdos o que é acessório ou secundário. Os livros didáticos e outros materiais de apoio ao professor têm uma proposta inicial de temas a serem trabalhadas de modo articulado e seqüencial, em cada um dos anos escolares, coerentes com os seus pressupostos teóricos e metodológicos dos autores que procuram seguir, as orientações curriculares da política oficial. Mas essa proposta explicitada nos materiais e textos didáticos, não serve ao professor ou ao aluno. Não são materiais para serem seguidos a risca ou definidores do trabalho docente a ser realizado. (CAVALCANTI, 2012, p. 131).

Os professores precisam usar de autonomia e distanciamento para que os materiais sirvam de apoio ao trabalho docente, não para defini-lo. Segundo Cavalcanti (2012, p. 142), “ensinar uma matéria depende não apenas de métodos didáticos, mas de outros tipos de métodos, como o método cientifico, os métodos da cognição e os métodos particulares das ciências." Portanto, o professor ao planejar uma aula precisa ter conhecimento para selecionar uma linha metodológica: positivismo; fenomenologia ou dialética como método cientifico e saber também como epistemologicamente os alunos aprendem, pois "pode-se afirmar que as visões de como o conhecimento ocorrem nos sujeitos dizem respeito à maneira de encaminhar as atividades do ensino" (p.142).

Deve ter clareza dos métodos particulares da ciência, saber qual ou quais correntes de pensamento geográfico ele pretende seguir. Tendo essa concepção, o professor terá que mediar o objeto encaminhando um trabalho de abstrações e generalizações, utilizando diversos elementos e processos mentais, para além da simples memorização e/ou constatação das propriedades e qualidades do objeto. Para alcançar na geografia escolar um olhar crítico e estimular o pensamento do aluno para fazer uma análise sobre a realidade.

\section{Orientações Curriculares e Educopédia no ensino de geografia na SME/RJ}

Desde 1990, o Governo Federal, Estados e Municípios têm trabalhado com as concepções de matriz de currículo por competências. O fundamento deste currículo é atribuir senso prático aos saberes disciplinares para desenvolver situações verificáveis e tarefas específicas.

As reformulações dos currículos são analisadas conforme o contexto de cada época, com o espaço vivido e produzido pela sociedade capitalista, permitindo, assim,

RIAEE - Revista Ibero-Americana de Estudos em Educação, Araraquara, v. 13, n. 1, p. 248-268, jan./mar., 2018. 
organizar e formular conteúdos e conceitos mediante a percepção dos professores sobre o que seja importante para o aprendizado de seu aluno e, principalmente, a concepção de ensino.

Couto (2014) relata que as atuais políticas educacionais reproduzem o processo de expansão com precarização da educação pública brasileira a atual conjuntura neoliberal visualizadas na finalidade de formação do trabalhador flexível e de consumidores (finalidade da educação) nas políticas de currículo a avaliação externa ações de controle da escola/professores, na política produtivista da meritocracia, de flexibilidade dos salários, condições de trabalho, visando otimizar custos em função de metas burocráticas.

O sistema neoliberal apresenta como pressuposto uma política de mercado que propaga a forma de crescimento econômico. Desta forma, quem precisa controlar a educação é a economia, ou seja, o Banco Mundial administra os projetos educacionais por meio de metas para garantir a diminuição de custo, ampliar e atender mais pessoas, com o propósito de minimizar a quantidade de pessoas fora das escolas.

A SME/ RJ informa que as Orientações Curriculares foram organizadas, a partir de discussões realizadas com professores da rede pública municipal de ensino, tendo como objetivo elencar conteúdos e objetivos que são centrais ao trabalho da Geografia Escolar. Além disso, tais orientações servem de amparo ao trabalho docente em temas, conceitos e processos clássicos da Geografia, articulando-os aos processos, dinâmicas e tendências atuais, com isso busca-se aproximação dessa Geografia Escolar aos avanços acadêmicos da ciência geográfica.

A seleção dos conteúdos está relacionada ao tipo de ser humano que se quer formar e também é uma disputa de poder sobre o que se pode e quer ensinar. Cada contexto histórico caracteriza formas políticas e econômicas nas quais diferem as organizações curriculares de uma disciplina, bem como a escolha dos conceitos e conteúdos e a dinâmica escolar, (LOPES; MACEDO, 2011).

Metodologicamente segundo a SME/RJ, para a disciplina Geografia buscou-se apresentar os processos e fenômenos geográficos em suas múltiplas escolaridades. Enfatizam- se os estudos sobre o Brasil e o Rio de Janeiro, estado e município, como recortes espaciais que aproximam a construção do conhecimento geográfico à realidade do aluno. Ademais se elenca um conjunto de "habilidades" consideradas como 
fundamentais pela SME/RJ à formação cidadã, com ênfase no domínio da linguagem cartográfica, gráfica, imagética.

A SME/RJ ao se referir as habilidades já expressa uma concepção de matriz curricular baseada por competências e habilidades. Compreendida por comportamentos mensuráveis e cientificamente controláveis. Ações executadas com base em habilidades, buscando indicadores de desempenho para avaliação, desconsiderando as relações sociais cotidianas dos alunos que são substituídas por competências técnicas de saberes especializados.

As habilidades e atividades propostas de acordo com a SME/RJ não são fórmulas para o trabalho do professor, constituir-se-iam em orientações, sugestões, para auxiliar o trabalho docente nas aulas de Geografia, uma vez que: “É um documento que, sem ser normativo, no sentido de sua obrigatoriedade, é diretivo, no sentido de que deve nortear o trabalho docente.

As Orientações Curriculares, não pretendem ser, portanto, um manual que engessa o trabalho do docente, mas ousam no sentido de estabelecer eixos norteadores ao trabalho do conjunto dos professores da rede municipal de ensino. Também não devem ser confundidas com o currículo do Município do Rio de Janeiro, a Multieducação: é um importante complemento. (SME/RJ, 2016).

Os objetivos, os conteúdos e as habilidades (figura 1) baseados nos Descritos Pedagógicos do Ministério da Educação e coadunados, como dito, à "Multieducação", foram especialmente trabalhados numa linguagem direta, procurando a melhor adequação a cada segmento. Para SME/RJ a multieducação é:

O Núcleo Curricular Básico MULTIEDUCAÇÃO seria a materialização da escola no cotidiano da ação pedagógica, no encontro dos atores sociais envolvidos no ato de ensinar e aprender e na possibilidade de desenvolvimento que se faz presente a cada aula, a cada planejamento, a cada centro de estudos. (SME/RJ, 1996).

Figura 1: Quadro das Orientações Curriculares da SME/RJ

RIAEE - Revista Ibero-Americana de Estudos em Educação, Araraquara, v. 13, n. 1, p. 248-268, jan./mar., 2018. 


\begin{tabular}{|c|c|c|c|c|c|c|c|}
\hline \multicolumn{8}{|c|}{ ORIENTAÇÓES CURRICULARES PARA O ENSINO DE GEOGRAFIA - $6 .^{\circ}$ ANO } \\
\hline \multirow{2}{*}{ OBJETIVOS } & \multirow{2}{*}{ CONTEÚdOS } & \multirow{2}{*}{ HABILIDADES } & \multicolumn{4}{|c|}{ BIMESTRES } & \multirow{2}{*}{ SUGESTŌES } \\
\hline & & & $10^{\circ}$ & $20^{\circ}$ & $30^{\circ}$ & $4 .^{\circ}$ & \\
\hline $\begin{array}{l}\text { Reconhecer fenômenos } \\
\text { e processos } \\
\text { socioespaciais, } \\
\text { tomando como centrais } \\
\text { os conceitos de lugar e } \\
\text { paisagem. }\end{array}$ & $\begin{array}{l}\text { PAISAGEM: } \\
\text { municipio do Rio de } \\
\text { Janeiro e estado do Rio } \\
\text { de Janeiro. }\end{array}$ & $\begin{array}{l}\text { Reconhecer elementos naturais } \\
\text { e humanizados presentes na } \\
\text { paisagem retratada em } \\
\text { iconografias ou observada em } \\
\text { trabalhos de campo. } \\
\text { Distinguir, em iconografias, } \\
\text { paisagens naturais e } \\
\text { humanizadas, urbanas e rurais. } \\
\text { Identificar os principais } \\
\text { elementos da paisagem da } \\
\text { cidade do Rio de Janeiro e do } \\
\text { estado do Rio de Janeiro, } \\
\text { retratada em iconografias ou } \\
\text { observada em trabalhos de } \\
\text { campo, tendo por base as } \\
\text { vivências e os conteúdos } \\
\text { adquiridos pelos alunos de } 4 . .^{\circ} \\
\text { e } 5^{\circ} \text { anos. } \\
\text { Reconhecer o espaço } \\
\text { geográfico como resultado da } \\
\text { interaçăo das sociedades com a } \\
\text { natureza. } \\
\text { Reconhecer o papel das } \\
\text { sociedades na transformação } \\
\text { do espaço geográfico, } \\
\text { percebendo-se com agente } \\
\text { ativo da construçăo do seu } \\
\text { próprio espaço. }\end{array}$ & $\mathrm{X}$ & & & & $\begin{array}{l}\text { Usar o site "ARMAZENZINHO" da Prefeitura } \\
\text { do Rio de Janeiro para buscar informaç̋̃es } \\
\text { sobre cada bairro da cidade, especialmente } \\
\text { daquelas áreas habitadas pelos alunos. } \\
\text { Pedir para cada aluno pesquisar sobre um } \\
\text { bairro da cidade que ele não conheça, mas que } \\
\text { tenha muita curiosidade de visitar. } \\
\text { Utilizar o google maps a fim de reconhecer os } \\
\text { municipios da Região Metropolitana, } \\
\text { estimulando o aluno a conhecer virtualmente } \\
\text { um deles. Criar painéis fotográficos com o } \\
\text { bairro ou a comunidade em que o aluno reside, } \\
\text { o bairro que gostaria de visitar e a cidade } \\
\text { vizinha que gostaria de conhecer. } \\
\text { Sugerir a montagem de um mural que expresse } \\
\text { a diversidade de identidades, presentes no } \\
\text { espaço da cidade do Rio de Janeiro. É de suma } \\
\text { importância o aluno relacionar a representação } \\
\text { espacial à realidade social. } \\
\text { Fazer um levantamento sobre o papel da } \\
\text { Prefeitura, do Governo Estadual e das } \\
\text { Associaçøes comunitárias no dia a dia do } \\
\text { aluno: quem é responsável pela coleta de lixo, } \\
\text { pela segurança pública, pela educação, pela } \\
\text { saúde, por representar os anseios dos } \\
\text { moradores de uma comunidade etc. }\end{array}$ \\
\hline
\end{tabular}

Fonte: SME/RJ (2016)

Os centros de estudos quando realizados não acontecem como citado pela $\mathrm{SME} / \mathrm{RJ}$, pois acabam sendo espaços de reclamações da direção e para preenchimento de documentos, relatórios de alunos não existe o efetivo planejamento de estratégias para alcançar a realidade dos alunos e suprir as demandadas das escolas e professores.

De acordo com a SME/RJ, a Geografia, enquanto área do conhecimento humano, com seu corpo teórico e conceitual, tem muito a contribuir para uma leitura de mundo que colabore na formação cidadã do alunado. Com tal objetivo, a disciplina tem um importante fator na formação do aluno como sujeito ativo deste mundo, no aprendizado, na sua auto-identificação e na construção de uma nova sociedade, com uma nova visão em questões sócio-ambientais.

O novo aluno deve ser o resultado de uma multiplicidade de fatores, pensamentos, sensações, construções teóricas e ações pedagógicas. As Orientações Curriculares foram, pois, retrabalhadas tendo em vista tal objetivo. Acreditamos desse modo, poder contribuir para a formação do jovem que está inserido e deverá participar mais ativamente nesta sociedade transformada, dinâmica e complexa (SME/RJ, 2016).

Os órgãos governamentais responsáveis pelas formulações curriculares oficiais brasileiras organizam, a partir do currículo por competências, a SME/RJ desenvolve a mesma estratégia de organização curricular. Ao analisaras orientações curriculares da 
SME/RJ e observar os elementos predominantes como objetivos, competências e habilidades voltadas para o saber-fazer e reconhecer conteúdos da geografia organizados de forma tradicional, como destacados por Lopes (2008). Observa-se que os alunos precisam reconhecer e identificar os elementos geográficos, de conteúdos específicos, mas não associados aos aspectos do cotidiano. As sugestões de trabalho em sala para o professor aparentemente apresentam relação com o cotidiano do aluno, mas apenas de forma parcial como reconhecimento das diversidades e uso de tecnologias sem o crítico ao poder hegemônico estabelecido.

O ensino desta disciplina ainda caracterizado de acordo com os interesses de Governo e de suas Políticas Públicas para a Educação e os conteúdos não relacionados à realidade e nem a qualquer crítica relacionada ao Estado. Mas ainda sem nenhuma relação imediata com o cotidiano dos alunos ou gerando uma crítica as desigualdades sociais provocadas pelo sistema capitalista.

Com relação ao conteúdo geográfico continua apresentando o padrão N-H-E (Natureza, Homem e Economia) descrito por Moreira (2014). Uma geografia descritiva, com valorização do empírico (observação, identificação, caracterização) antes da teoria, e acontecimentos divididos em aspectos físicos, aspectos humanos e aspectos econômicos, que vem se arrastando como discurso pedagógico enciclopédico

Neste debate, os avanços tecnológicos estão também inseridos e tem-se buscado hoje, pela mídia, internet e/ou imagens de satélites, conteúdos ou ferramentas que retratem o cotidiano do mundo. A escola como responsável pela construção de conhecimento, precisa estar atenta e se apropriar dessas tecnologias como instrumentos para decodificar, analisar e interpretar fenômenos nos quais os alunos precisam ter a capacidade de fazer a leitura.

Segundo Bittencourt; Albino (2017) as novas tecnologias se encontram presentes na vida cotidiana dos estudantes, sendo assim, a escola deveria preparar e desenvolvêlos para uma atuação crítica em frente às novas informações e situações que emergem a todo o momento.

Estes autores analisam que a utilização de recursos tecnológicos mais avanços se torna uma estratégia de ensino e aprendizagem em diferentes instituições, como forma de articular os conceitos e os conteúdos propostos nos diferentes currículos, propostas ou orientações curriculares.

RIAEE - Revista Ibero-Americana de Estudos em Educação, Araraquara, v. 13, n. 1, p. 248-268, jan./mar., 2018. 
Desta forma, a Secretaria de Educação do Município do Rio de Janeiro em consonância com as mudanças ocorridas na educação, cria segundo Andrade; Sacramento; Souza (2016) a Educopéia é uma plataforma educacional on-line, com aulas digitais, na qual estudantes e professores podem acessar atividades autoexplicativas de qualquer lugar e a qualquer hora. Este projeto foi desenvolvido em parceria com o Instituto OI Futuro, no ano de 2010.

A plataforma consiste em atividades que incluem temas/conteúdos, com as respectivas competências, divididas em trinta e duas aulas digitais, por diferentes disciplinas, no nosso caso, destaca-se a Geografia, correspondentes às semanas do ano letivo. "Vídeos, animações, imagens, textos, podcasts, quiz e jogos estão inseridos nas atividades. $\mathrm{O}$ material educativo on-line é disponibilizado para alunos e professores da rede pública de ensino da cidade, que podem consultar essas informações de qualquer computador e a qualquer hora, através do endereço eletrônico http://www.educopedia.com.br. (figura 2).

Figura 2: Página inicial da Educopédia

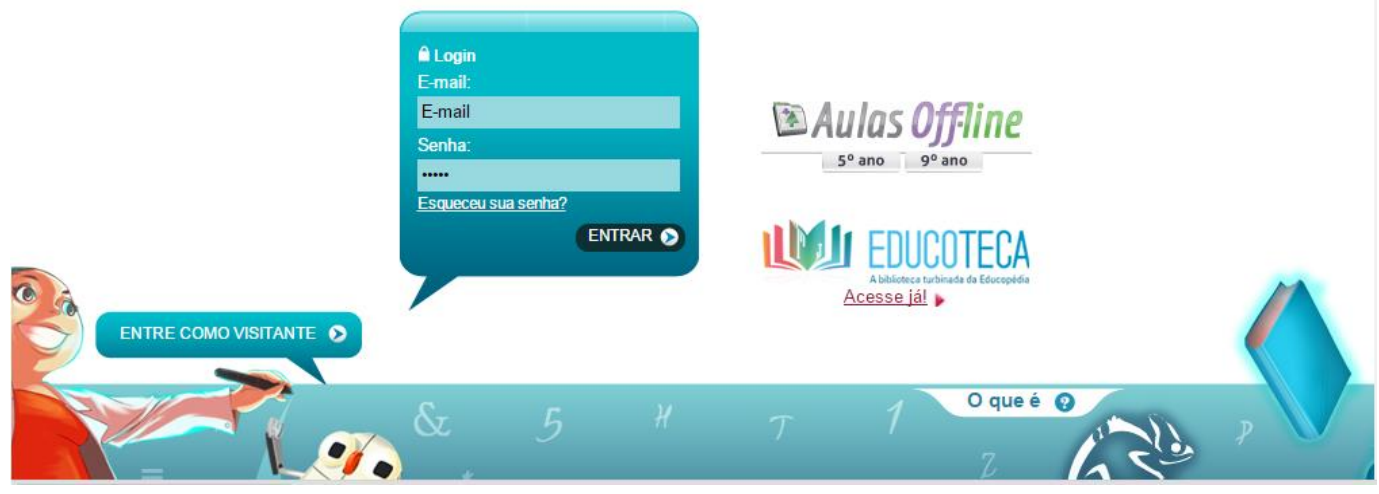

Fonte: Educopédia (2015)

Além disso, a plataforma atende as Orientações Curriculares da SME-RJ, porque respondem as políticas públicas educacionais e são responsáveis pela organização das escolas, das disciplinas (figura 3), dos materiais e do pessoal que são financiados por estes. 
Figura 3: Seleção da disciplina geografia

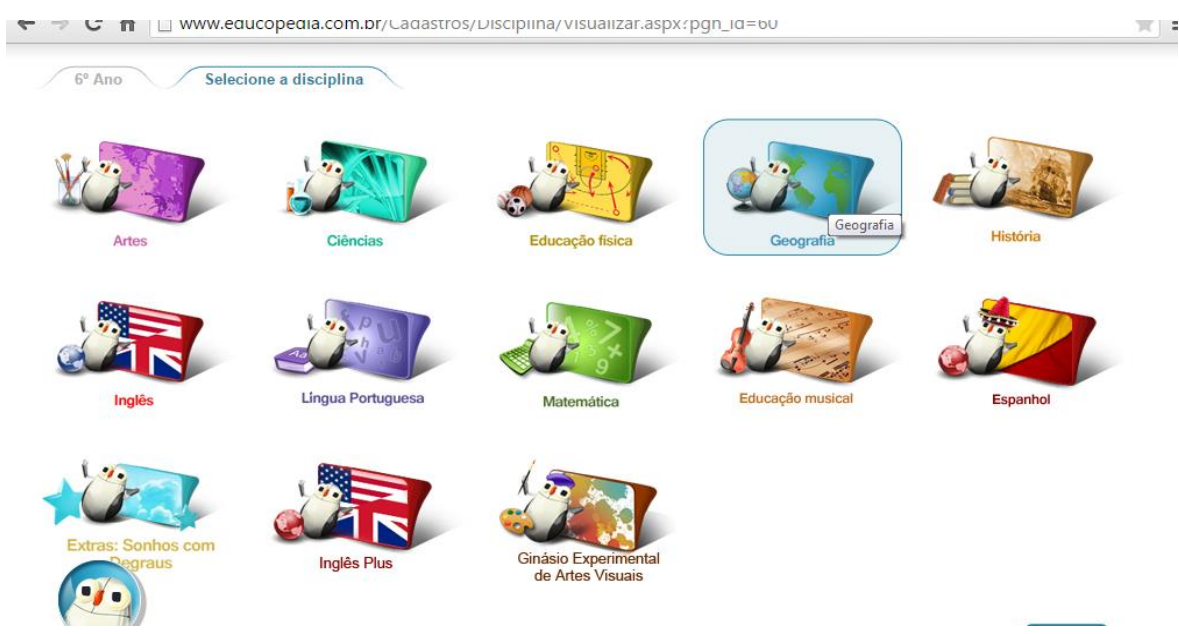

Fonte: Educopédia (2015)

De acordo com a SME/RJ uma característica importante dessa experiência é a integração do currículo com o material didático utilizado para apoiar o /2015trabalho do professor em sala de aula. O material educativo online é disponibilizado para alunos e professores da rede pública de ensino da cidade, que podem consultar essas informações de qualquer computador e a qualquer hora, através do endereço eletrônico, (figuras 4).

Figura 4: Conteúdo da Educopédia

\begin{tabular}{|c|c|c|c|c|c|}
\hline \multicolumn{2}{|c|}{$6^{0} \mathrm{Ano}$ | Geografia } & \multicolumn{4}{|c|}{ 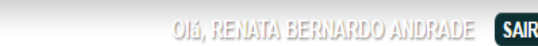 } \\
\hline \multicolumn{6}{|c|}{$1^{\circ}$ Bimestre } \\
\hline Ordem & Nome da aula & Qtd. atividades & Plano & Apresentaçäo & Habilidades \\
\hline 1 & Paisagem Geográfica: conceituação e tipificaç & 31 & 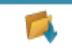 & $a$ & 田 \\
\hline 2 & Espaço Geográfico: conceito e relação com pai & 28 & $a$ & $a$ & 固 \\
\hline 3 & Lugar, vizinhança e localização & 29 & $a$ & $a$ & 줍 \\
\hline 4 & Orientação espacial num lugar & 30 & $\square$ & a & 田 \\
\hline 5 & Formas de representação cartográfica & 34 & $a$ & a & 줌 \\
\hline 6 & Escalas & 29 & $a$ & a & 田 \\
\hline 7 & Coordenadas geográficas & 31 & $a$ & $a$ & 줍 \\
\hline 8 & Leitura e interpretação de mapas & 27 & $a$ & a & 줌 \\
\hline
\end{tabular}

Fonte: Educopédia (2015)

RIAEE - Revista Ibero-Americana de Estudos em Educação, Araraquara, v. 13, n. 1, p. 248-268, jan./mar., 2018 
O avanço da reflexão e dos conhecimentos geográficos para superar esse empirismo de tradição da área contribui para colocar novos elementos da reflexão no campo da didática e da metodologia do ensino de geografia.

Para Cavalcanti (2014) a ciência geográfica tem buscado uma pluralidade de abordagens do objeto estudado, ao aceitar que elas são sempre subjetivas e dependem de fundamentos teóricos, que conhecimentos científicos são históricos, subjetivos construídos, então a reprodução imediata da realidade empírica, no âmbito das práticas de ensino desses conhecimentos, essa compreensão não pode ser considerada uma maneira de abordar esse conhecimento com os alunos é apresentada-lo como construções humanas e históricas que buscam compreender a realidade por um caminho próprio, com a centralidade de uma categoria de um instrumento mediador dessa construção.

O espaço geográfico, ou a espacialidade no ensino é também um desafio escapar da ilusão do empirismo e buscar métodos para abordar didaticamente os temas geográficos que possam efetivamente contribuir para o desenvolvimento do pensamento teórico-crítico dos alunos. (CAVALCANTI, 2014, p. 140).

Entender o papel da escola e do currículo na formação da sociedade é importante para definir quais caminhos metodológicos devem ser seguidos durante a prática de ensino, (CASTELLAR; STEFENON, 2015). Sendo assim, o que difere a escola da família e de outros espaços de educação?

Segundo Young (2007), na escola existe a garantia de acesso ao conhecimento poderoso, "esse conceito não se refere a quem tem mais acesso ao conhecimento ou quem o legitima [...], refere-se ao que o conhecimento pode fazer, como por exemplo, fornecer explicações confiáveis ou novas formas de se pensar a respeito do mundo" (YOUNG, 2007, p. 1294).

Mas, qual visão de mundo pretende-se desenvolver ao se ensinar geografia? Segundo Cavalcanti (2013), a escola tem tido como principal função o ensinamento da lógica formal, baseado no método da ciência moderna, de validação de veracidade científica a partir da linguagem matemática, em que a teoria somente aparece no final do processo como a resposta, por um caminho que percorre do concreto ao abstrato.

A proposta de substituição do modelo de escola (e de geografia na escola) que ensine nos moldes da lógica formal por uma que construa um raciocínio dialético, em 
que o aprendizado é entendido como fruto de um processo de contradições entre saberes prévios e novos saberes.

É preciso que o processo de ensino-aprendizagem comece na realidade dos alunos e retorne para a mesma, mas como realidade conceitualmente pensada. Isso porque os conceitos trabalhados pela geografia, como espaço, lugar, paisagem, território, região, dentre outros, fazem parte do cotidiano das pessoas.

A aprendizagem dos conteúdos/conceitos deve ser condição para que se formule uma resposta ao problema proposto, que possua valor sócio - cultural - espacial real e ao mesmo tempo se relacione com os conteúdos do ensino. Desta forma, a geografia caberia a função de ampliar o processo de letramento, próprio da escola fundamental, na medida em que desenvolve a alfabetização geográfica, isto é a apropriação dos sentidos do mundo pelos conteúdos e conceitos da geografia.

\section{Considerações finais}

Este texto propõe pensar o currículo como um instrumento de determinação de quais conhecimentos são válidos e devem ser ensinados aos alunos, e a importância de se problematizar este tema, a partir das concepções teóricas do ponto de vista das teorias curriculares bem como da organização curricular.

A partir disso, o currículo de Geografia é parte de uma concepção curricular que visa analisar que tipo de disciplina deve estar nos currículos da escola básica, defendendo uma que ensine os alunos uma leitura de mundo e das suas espacialidades diferenciais existentes. A Geografia, bem instrumentado metodologicamente, promove um ensino crítico aos alunos na compreensão de múltiplas determinações e as diferentes escalas que influenciam sua realidade, para assim poder intervir na mesma, tornando-se sujeitos ativos de sua própria história.

Ao analisar as Orientações Curriculares da SME e da Educopédia em seu conteúdo curricular seus objetivos, competências e habilidades que refletem um currículo tradicional e baseado na matriz de currículo por competência uma tendência da política educacional mundial devido ao neoliberalismo.

Desta forma, um currículo voltado para formar um tipo de trabalhador polivalente, flexível, promovendo uma educação por meio de habilidades e estabelecendo que as escolas tenham metas estipuladas de forma mercadológica. Com objetivos e prioridades transformando a escola e suas práticas devido aos avanços

RIAEE - Revista Ibero-Americana de Estudos em Educação, Araraquara, v. 13, n. 1, p. 248-268, jan./mar., 2018. 
tecnológicos e mudanças no trabalho docente de mediador para tutor ou aplicador de métodos prontos cerceando o mesmo da reflexão sobre o seu oficio de professor.

\section{REFERÊNCIAS}

ANDRADE, R. B.; SACRAMENTO, A. C. R._Educopédia: uma forma de ensinar geografia. In: $1^{a}$ Jornada Ibero-Americana de Pesquisas em Políticas Educacionais e Experiências Interdisciplinares na Educação, 2016, Brasília: Grupo Nova Paideia, Anais... 2016. p. 605-611.

BITTENCOURT, P. A. S.; ALBINO, J. P. O uso das tecnologias digitais na educação do século XXI. Revista Ibero-Americana de Estudos em Educação, v.12, n. 1, p. 205-214, jan./mar., 2017., 2017. DOI: 10.21723/riaee.v12.n1.9433.

CASTELLAR, S. M. V. A importância da Geografia no Currículo e no contexto escolar. In: PAES, M. T.; SILVA, C.; MATIAS, L. (orgs). (Org.). Geografia, políticas Públicas e Dinâmicas Territoriais. $1^{\mathrm{a}} \mathrm{ed}$. Dourados: Universidade Federal Grande Dourados, 2013, v. 1, p. 3-26.

CASTELLAR, S. M. V.; STEFERON, D. L. A ciência Geográfica na escola: pressupostos de um currículo escolar fundamentado no conhecimento disciplinar. Unipluri (Medellin), v. 15, p. 15-23, 2015.

CAVALCANTI, L. S. Geografia, escola e construção do conhecimento. $18^{\mathrm{a}} \mathrm{ed}$. Campinas, SP: Papirus, 2013.

CAVALCANTI, L. S. Ensino de geografia na escola. Reimpressão. $3^{\text {aed., }} 2014$.

LACOSTE. Y. A Geografia - isso serve, em primeiro lugar, para fazer a guerra. 19ªed. Campinas, SP: Papirus, 2012.

LOPES, A. R. C. Políticas de integração curricular. Rio de Janeiro: EdUERJ, 2008.

LOPES, A. C.; MACEDO, E.Teorias do Currículo. São Paulo: Cortez, 2011.

MALTA, S. C. L. Uma abordagem sobre currículo e teorias afins visando à compreensão e mudança. Revista Espaço do Currículo (Online), v. 6, p. 340-354, 2013.

MOREIRA, R. Para onde vai o pensamento geográfico. 1a.. Ed.São Paulo: Contexto, 2006.

MOREIRA, R. O discurso do avesso: para a crítica da geografia que se ensina. 2a. Ed. São Paulo: Editora Contexto, 2014. 
SECRETARIA MUNICIPAL DE EDUCAÇÃO DO RIO DE JANEIRO. Orientações Curriculares de Geografia SME/RJ, 2016. Disponível em

http://www.rioeduca.net/blogViews. Php?id=5265. Acesso em: 10 mar. 2017.

SECRETARIA MUNICIPAL DE EDUCAÇÃO DO RIO DE JANEIRO. Núcleo Curricular Básico MULTIEDUCAÇÃO. Rio de Janeiro, 1996.

SILVA, T. T. da (org). Teoria do currículo. In: Documentos de identidade: uma introdução às teorias do currículo. Belo Horizonte: Autêntica, 1999, p. 11-17.

YOUNG, M. Para que serve as escolas? Educ. Soc., Campinas, vol. 28, n. 101, set./dez., 2007, p. 1287-1302.

\section{Como referenciar este artigo}

ANDRADE, Renata Bernardo.; SACRAMENTO, Ana Claudia Ramos. Orientações curriculares de geografia e educopédia da Secretaria Municipal de Educação do Rio de Janeiro. Revista Ibero-Americana de Estudos em Educação, Araraquara, v. 13, n. 1, p. 248-268, jan./mar., 2018. E-ISSN: 1982-5587.

Submetido em: 14/05/2017

Revisões requeridas: $17 / 09 / 2017$

Aceito em: 16/11/2017 